\title{
La responsabilidad paterna para embriones producidos en un ciclo de reproducción humana asistida: un análisis a la luz del principio de paternidad responsable
}

Parental responsibility regarding the embryos produced in a cycle of assisted human reproduction: an analysis in the light of the principle of responsible parenthood

Autores: Carlos Alexandre Moraes, Tatiana de Freitas Giovanini Mochi, Juan Ramón Pérez Carrillo

DOl: https://doi.org/10.25058/1794600X.1793 


\title{
LA RESPONSABILIDAD PATERNA PARA EMBRIONES PRODUCIDOS EN UN CICLO DE REPRODUCCIÓN HUMANA ASISTIDA: UN ANÁLISIS A LA LUZ DEL PRINCIPIO DE PATERNIDAD RESPONSABLE*
}

\author{
Parental responsibility regarding the embryos produced in a \\ cycle of assisted human reproduction: an analysis in the light of \\ the principle of responsible parenthood \\ Responsabilidade paterna para embriões produzidos em um \\ ciclo de reprodução humana assistida: uma análise à luz do \\ princípio da paternidade responsável
}

\author{
Carlos Alexandre Moraes ${ }^{a}$ \\ camoraes.adv@hotmail.com \\ Tatiana de Freitas Giovanini Mochi ${ }^{\text {b }}$ \\ tatifgi@hotmail.com \\ Juan Ramón Pérez Carrilloc \\ jramoncuba@gmail.com
}

Fecha de recepción: 23 de abril de 2020 Fecha de revisión: 04 de mayo de 2020 Fecha de aceptación: 08 de mayo de 2020

\section{DOI: https://doi.org/10.25058/1794600X.1793}

Para citar este artículo:

Para citar este artículo:
Moraes, C. A.; Mochi Giovanini, T. y Pérez Carrilo, J. R. (2020). La responsabilidad paterna para embriones producidos en un ciclo de reproducción humana asistida: un análisis a la luz del principio de paternidad responsable. Revista Misión Jurídica, 13, (19), 170-186.

\section{RESUMEN}

Es derecho de todo ciudadano tener una libre planificación familiar, sin embargo, el uso de técnicas de fertilización artificial también debe estar vinculado al principio de la paternidad responsable y de la dignidad de la persona humana, lo que también implica la responsabilidad en relación al destino de todos los embriones producidos en la fertilización in vitro. La Ley de Bioseguridad, objeto de la Acción Directa de Inconstitucionalidad (ADI) no. 3.510, juzgado sin

\footnotetext{
*Artículo de reflexión.

a. Professor Permanente do Programa de Doutorado e Mestrado em Direito do Centro Universitário Cesumar (UniCesumar); Pós-Doutor em Direito pelo Centro Universitário Cesumar (UniCesumar), Doutor em Direito pela FADISP; Doutor em Ciências da Educação pela UPAP; Mestre em Direito pelo Centro Universitário Cesumar (UniCesumar); Pesquisador Bolsista - Modalidade Produtividade em Pesquisa para Doutor PPD - do Instituto Cesumar de Ciência, Tecnologia e Inovação (ICETI); Advogado.

b. Mestra em Ciências Jurídicas pelo Centro Universitário Cesumar - Unicesumar, professora do Curso de Bacharelado em Direito do Centro Universitário Cesumar - Unicesumar, advogada.

c. Profesor Investigador Titular de la Carrera de Derecho, Universidad San Gregorio de Portoviejo, Ecuador. Doctor en Ciencias Jurídicas por la Universidad de Oriente, Cuba.
} 
fundamento por el Supremo Tribunal Federal (STF), llegó a regular la posibilidad de que los embriones excedentes de un ciclo de fertilización estén destinados a la investigación científica.

Sin embargo, la ley tiene inconsistencias, como la redacción del artículo III del art. 5to. Además, el STF adoptó una visión utilitaria no solo del embrión sino también del principio de la dignidad de la persona humana, que culmina en la cosificación del propio ser humano. Debe existir una responsabilidad por parte de quienes están dispuestos a tener un hijo artificialmente, y esto se deriva del principio de la paternidad responsable, y por lo tanto es necesario limitar, por ejemplo, el número de embriones producidos en cada ciclo de fertilización, entre otras medidas que sobresalen en el respeto a la vida humana.

\section{PALABRAS CLAVE}

Planificación familiar; paternidad responsable; embrión; reproducción asistida.

\section{ABSTRACT}

It is the right of every citizen to have free family planning, nonetheless, the use of artificial fertilization techniques should also be associated with the principle of responsible parenthood and of human dignity, which also implies the responsibility regarding the destination of every embryo produced in in vitro fertilization. Biosecurity Law, subject of the Direct Action of Unconstitutionality (ADI) no. 3.510, unsupportedly judged by the Federal Supreme Court (STF) got to regulate the possibility that the surplus embryos of a fertilization cycle are destined to scientific research.

However, this law has inconsistencies such as the wording of article III of art. 5. Furthermore, the STF adopted a utilitarian vision not only of the embryo but also with the principle of human dignity which culminates in the commodification of human beings. There must be a responsibility on the part of those whom are willing to have a child artificially and this derives in the principle of responsible parenthood, thus it is necessary to limit, for example the quantity of embryos produced on each fertilization cycle, among other measures that surpass respect for human life.

\section{KEYWORDS}

Family Planning. Responsible Parenthood. Embryo. Assisted Reproduction.

\section{RESUMO}

É direito de todo cidadão o planejamento familiar gratuito, porém, a utilização de técnicas de fertilização artificial também deve estar vinculada ao princípio da paternidade responsável e à dignidade da pessoa humana, o que implica também responsabilidade em relação ao destino de todos os embriões produzidos na fertilização in vitro. A Lei de Biossegurança, objeto da Ação Direta de Inconstitucionalidade (ADI) no 3.510, julgado sem fundamento pelo Supremo Tribunal Federal (STF), veio regulamentar a possibilidade de os embriões excedentes de um ciclo de fecundação serem destinados à pesquisa científica.

No entanto, a lei apresenta inconsistências, como a redação do art. III do art. 5a . Além disso, o STF adotou uma visão utilitária não só do embrião, mas também do princípio da dignidade da pessoa humana, culminando na reificação do próprio ser humano. Deve haver uma responsabilidade por parte de quem deseja ter um filho artificialmente, e isso decorre do princípio da paternidade responsável, sendo necessário limitar, por exemplo, o número de embriões produzidos em cada ciclo de fecundação, entre outras medidas que primam pelo respeito à vida humana.

\section{PALAVRAS-CHAVE}

Planejamento familiar; paternidade responsável; embrião; reprodução assistida.

\section{INTRODUCCIÓN}

El uso de técnicas de reproducción humana asistida y su creciente demanda han generado discusiones sobre las implicaciones que estas nuevas formas de fertilización pueden implicar para la sociedad. Por lo tanto, es esencial analizar el tema a partir de una revisión bibliográfica del derecho a la libre planificación familiar, asociado con el principio de la paternidad responsable y la dignidad de la persona humana, a fin de comprender si la responsabilidad parental en la realización del proyecto parental debe, o 
no, abarcar las primeras etapas del desarrollo humano, esto es, desde la formación del embrión.

Preliminarmente, es necesario analizar la vulnerabilidad del embrión y la necesidad de protegerlo o no. Tal cuestionamiento conduce al destino de los embriones excedentes de un ciclo de fertilización in vitro y a la regulación dada por la Ley de Bioseguridad. Por lo tanto, se pretende realizar una interpretación del art. 5 de la mencionada ley, así como la Acción Directa de Inconstitucionalidad n. $\stackrel{0}{ }$ 3.510, juzgado sin fundamento por el Supremo Tribunal Federal por mayoría de votos.

El decisum de la Corte Constitucional brasileña se basó, entre otros argumentos, en el principio de la dignidad humana. Sin embargo, considerará la visión utilitaria que el Supremo ha tomado con respecto a tal principio, es decir, al considerar al embrión como un medio para lograr mayores fines.

Finalmente, se abordará la responsabilidad parental en relación a los embriones derivados de las técnicas de reproducción asistida, especialmente los que no fueran implantados en el útero. La discusión, por lo tanto, enfatizará si limitar o no el número de ovocitos fertilizados en cada ciclo, el uso del diagnóstico genético preimplantacional para la selección de bebés "a medida" y el destino de los embriones que se han convertido en excedentes.

\section{LA PLANIFICACIÓN FAMILIAR ASOCIADA AL EJERCICIO DE PATERNIDAD RESPONSABLE EN TÉCNICAS DE REPRODUCCIÓN HUMANA ASISTIDA}

Las causas de la infertilidad están más allá del control humano, y muchas parejas necesitarán recurrir a técnicas de reproducción humana asistida. Según las estadísticas, el 20\% de la población mundial es infértil y, según la secuencia del genoma humano, esta infertilidad se transmitirá a las generaciones futuras ${ }^{1}$.

Las técnicas de reproducción humana asistida ayudan en la fertilización humana y pueden conceptualizarse como el conjunto de técnicas que permiten la fertilización humana a través de

1. CRUZ, Ivelise Fonseca da. Efeitos da reprodução humana assistida. São Paulo: SRS Editora, 2008. la manipulación de gametos y embriones, con el fin de generar el nacimiento de un nuevo ser.

Tanto la infertilidad como la esterilidad están previstas en la Clasificación Internacional de Enfermedades de la Organización Mundial de la Salud, ICD 10, y por lo tanto se consideran un problema de salud pública tratable. Algunas de las técnicas más utilizadas para abordar estos problemas son: inseminación artificial, fertilización in vitro y maternidad subrogada, etc.

Cada año, el número de parejas que utilizan técnicas de fertilización artificial para la planificación familiar es mayor, debido a cierta incapacidad en la concepción natural de un niño. Esto se debe a que, según los datos presentados por Juliane Fernandes Queiroz, la infertilidad afecta a entre el 10 y el 15\% de las parejas en edad reproductiva, y en el $40 \%$ de los casos se estima que la causa del problema está asociada con las mujeres, $40 \%$ para el hombre, y el $20 \%$ restante para la pareja o por alguna razón desconocida ${ }^{2}$.

Según las estadísticas de la Red Latinoamericana de Reproducción Asistida (RED), en 1999 había noventa y cinco centros o clínicas que realizaban inseminación artificial o procedimiento de fertilización in vitro en toda América Latina ${ }^{3}$. En 1990, este número era solo de $21^{4}$. Por otro lado, en 2009 , han sido reportados 135 centros de reproducción en once países ${ }^{5}$.

La reproducción asistida puede conceptualizarse como el "conjunto de técnicas que favorecen la fertilización humana, mediante la manipulación de gametos y embriones, principalmente con el objetivo de combatir la infertilidad y proporcionar el nacimiento de una nueva vida humana ${ }^{6 "}$.

2. QUEIROZ, Juliane Fernandes. Paternidade: aspectos jurídicos e técnicas de inseminação artificial. Belo Horizonte: Del Rey, 2001, p. 67.

3. RED LATINOAMERICANA DE REPRODUCCIÓN ASISTIDA. Registro Latinoamericano de Reproducción Asistida de 1999: 10 años. Disponível em: <http://www.redlara.com/ aa_portugues/registro_anual.asp?categoria=Registros Anuais\&cadastroid=23>. Acesso em 26 ago. 2019 .

4. Ibid.

5. Ibid

6. RODRIGUES JUNIOR, Walsir Edson Rodrigues; BORGES, Janice Silveira. Alteração da vontade na utilização das técnicas de reprodução assistida. In: TEIXEIRA, Ana Carolina Brochado; RIBEIRO, Gustavo Pereira Leite (Coord.). Manual de direito das famílias e das sucessões. Belo Horizonte: Del Rey: Mandamentos, 
Existen varias técnicas de reproducción asistida, como la inseminación artificial intrauterina, la transferencia tubular de gametos y embriones, la inyección intracitoplasmática de esperma y la fertilización in vitro, la diferencia entre estos procedimientos es la complejidad, el costo financiero e indicación terapéutica ${ }^{7}$.

A través de la inseminación artificial, los espermatozoides se introducen en el canal genital femenino mediante procesos mecánicos sin la práctica de un acto sexual. Es una técnica simple cuyo uso se remonta a la Edad Media ${ }^{8}$. La expresión "inseminación" tiene su origen en la frase latina "inseminare", "in" (que significa, dentro) y "semem" (que significa semilla").

Además de la inseminación artificial, la fertilización in vitro se destaca como una de las técnicas más utilizadas en la actualidad. En este modo, la fertilización ocurre in vitro, es decir, la fertilización del óvulo por el esperma se realiza en el laboratorio y una vez que se forma el embrión, se transfiere al útero materno ${ }^{10}$.

El derecho a la planificación familiar estaba regulado en Brasil por la Ley n. ${ }^{-}$9.263, del 12 de enero de 1996, definido por el art. 1 como el conjunto de acciones dirigidas a la regulación de la fertilidad, a fin de garantizar la igualdad de derechos de constitución, limitación o aumento de la descendencia por parte de mujeres, hombres o parejas, prohibiendo el uso de estas medidas como forma de control de la natalidad.

Según la redacción del art. 9.어 de la mencionada ley, corresponde al Estado ofrecer todos los

\footnotetext{
$2008, p .22$.

7. RIBEIRO, Gustavo Pereira Leite. Breve comentário sobre aspectos destacados da reprodução humana assistida. In: SÁ, Maria de Fátima Freire de (Coord.). Biodireito. Belo Horizonte: Del Rey, 2002, p.28.

8. Juliane Fernandes Queiroz assevera que "Arnaud Villeneuve, médico de reis e papas, teria obtido sucesso na inseminação artificial com a introdução do esperma de Henrique IV, de Castela, em sua esposa", e que, outrossim, "relatos do século XVII registram que um monge italiano, chamado Spallanzini, já havia feito tentativas de inseminação". In: Paternidade: aspectos jurídicos e técnicas de inseminação artificial. Belo Horizonte: Del Rey, 2001, p. 71.

9. LEITE, Eduardo de Oliveira. Procriações artificiais e o direito: aspectos médicos, religiosos, psicológicos, éticos e jurídicos. São Paulo: Revista dos Tribunais, 1995, p. 3.

10. SÁ, Maria de Fátima Freire; NAVES, Bruno Torquato de Oliveira. Manual de Biodireito. Belo Horizonte: Del Rey, 2009, $p$. 111.
}

métodos y técnicas de diseño científicamente aceptados que no pongan en peligro la vida y la salud de las personas, para el ejercicio del derecho a la planificación familiar. Esto implica permitir que las parejas incapaces de concebir hijos de la manera natural recurran a técnicas de reproducción asistida, como una forma de asegurar la realización del proyecto de crianza.

Según el art. 226, §7 de la Constitución Federal, la planificación familiar es un derecho constitucionalmente garantizado para todos los ciudadanos, que, sin embargo, debe ejercerse sobre la base de los principios de dignidad humana y crianza responsable. Según José Pinto-Barros, la planificación familiar puede conceptualizarse como:

Correcto proceso de alcance, aprendizaje, conciencia, aplicación de técnicas y métodos anticonceptivos, clínicamente respaldado en el pleno respeto de los derechos de la persona humana, en plena satisfacción emocional-sexual y como resultado final del tamaño y estructura deseados de la familia, de acuerdo con las características paternal: psíquico, físico, social, económico y otros; traduciéndose en el número de hijos que una familia determinada quiere cuando quiere ${ }^{11}$.

Sin embargo, la planificación familiar asociada con la crianza responsable incluye no solo la decisión sobre el número de hijos, sino también el intervalo apropiado entre embarazos, la posibilidad de utilizar técnicas de reproducción asistida como último recurso para la procreación, la discusión sobre la reproducción de forma monoparental, inseminación post mortem, etc.

Clayton Reis argumenta que la generación de un hijo implica la responsabilidad de los padres, que deriva del poder familiar, según lo dispuesto en el art. 1.634 del Código Civil. Por lo tanto, aquellos que tienen la intención de tener un hijo deben considerar las consecuencias de su nacimiento, de modo que realicen los cuidados necesarios para el mantenimiento y la educación de este nuevo ser humano ${ }^{12}$.

11. PINTO-BARROS, José. Planeamento familiar: aborto e o direito. Coimbra: Coimbra, 1992, p. 37.

12. REIS, Clayton. O planejamento familiar: um direito de personalidade do casal. Revista Jurídica Cesumar - Mestrado, Maringá, v. 8, n. 2, p. 415-435, 2008. 
La crianza responsable proviene del ejercicio de los derechos reproductivos por parte de los seres humanos. Sin embargo, la libertad sexual de hombres y mujeres implica la responsabilidad del resultado de esta relación, es decir, son responsables de los embriones producidos a través de la reproducción asistida, y también del eventual nacimiento de uno o más hijos, incluso si no son deseados o planeados ${ }^{13}$.

Por lo tanto, es indispensable que las personas ejerzan su derecho de procreación y se relacionen sexualmente con la responsabilidad, ya que tienen el deber de cuidar al niño que puede ser concebido como resultado de esta relación. Por otro lado, si la pareja opta por la reproducción con asistencia médica, deben ser conscientes de que también serán responsables de todos los embriones producidos en el laboratorio.

Sobre la relación entre los derechos reproductivos, la planificación familiar y la crianza responsable, se cita la Conferencia Internacional sobre Población y Desarrollo celebrada en El Cairo, Egipto, del 5 al 13 de septiembre de 1994, que reunió a representantes de más de 180 gobiernos, incluido Brasil, así como 1.254 organizaciones no gubernamentales.

Al final de la Conferencia, la comunidad internacional estableció tres objetivos a alcanzar hasta 2015: (i) reducir la mortalidad infantil y materna; (ii) acceso a la educación, especialmente para niñas; y (iii) acceso universal a una amplia gama de servicios de salud reproductiva, incluida la planificación familiar ${ }^{14}$, tomada de la sección 7.6 del Programa de Acción de El Cairo:

7.6 Todos los países deberían, lo antes posible y no despues de 2015, esforzarse por hacer que la salud reproductiva sea accesible para todas las personas a edades apropiadas a través de un sistema de atención primaria de salud. El cuidado con salud reproductiva en el contexto de la atención primaria de salud debe incluir, inter alia: servicios de asesoramiento, información, educación,

13. GAMA, Guilherme Calmon Nogueira da. A nova filiação: o biodireito e as relaçóes parentais: o estabelecimento da parentalidade-filiação e os efeitos jurídicos da reprodução assistida heteróloga. Rio de Janeiro: Renovar: 2003, p. 453-454.

14. UNITED NATIONS. Internacional Conference on Population and Development. Disponível em: <http://www.un.org/popin/ icpd2.htm >. Acesso em 02 ago. 2019. comunicación y planificación familiar; educación y servicios prenatales, de parto seguro y de atención postnatal; prevención y tratamiento adecuado de la esterilidad; aborto como se especifica en el párrafo 8.25 , incluida la prevención del aborto y el tratamiento de sus secuelas; tratamiento de infecciones del tracto reproductivo e información, educación y asesoramiento, según sea necesario, sobre sexualidad humana, salud reproductiva y crianza responsable. Dichos servicios de planificación familiar y diagnóstico y tratamiento de complicaciones de embarazo, parto y aborto, esterilidad, infecciones del tracto reproductivo, cáncer de mama y cánceres del sistema reproductivo, incluidas las enfermedades de transmisión sexual, siempre deben estar disponibles según sea necesario. VIH / SIDA. Los desincentivos efectivos a las prácticas nocivas, como la mutilación genital femenina, deben ser una parte integral de la atención médica, incluidos los programas de atención de la salud reproductiva ${ }^{15}$.

La relevancia de la planificación familiar, ya sea que esté relacionada con el control de la natalidad o la búsqueda de formas artificiales de concepción, es permitir las condiciones más favorables para el nacimiento de un niño deseado y listo para ser recibido en un ambiente que está listo para recibirlo.

La Constitución Federal brasileña reconoce, por lo tanto, en el art. 226, §7, la importancia de la planificación familiar como una forma de proteger a la familia y a la sociedad misma, siempre que esté asociada con la dignidad de la persona humana y la paternidad responsable, lo que puede conceptualizarse como la obligación que los padres tienen de proporcionar asistencia moral, afectivos, intelectuales, materiales, sexuales y espirituales para sus hijos ${ }^{16}$.

Obviamente, el término "crianza responsable" no se limita a las obligaciones de la figura masculina de cuidar a los niños, sino que también cubre el papel materno en el desarrollo psicofísico

15. Ibid.

16. CARDIN, Valéria Silva Galdino. Do planejamento familiar, da paternidade responsável e das políticas públicas. IBDFAM, Belo Horizonte. Disponível em: <www.ibdfam.org.br>. Acesso em: 01 ago. 2019. 
de los bebés. Por esta razón, Guilherme Calmon Nogueira da Gama prefiere usar la palabra "crianza" para referirse a la responsabilidad que el padre y la madre tienen en la educación y la crianza de sus hijos ${ }^{17}$.

Según Clayton Reis, el deber de educar al bebé y transmitirle valores es solidario, es decir, no solo la madre que dio a luz al niño, sino también el hombre que ofreció su material genético ${ }^{18}$. Dicha obligación se inserta en el art. 229 de la Constitución Federal, que establece que "los padres tienen el deber de ayudar, criar y educar a sus hijos menores, y los niños mayores tienen el deber de ayudar y apoyar a sus padres en la vejez, la necesidad o la enfermedad".

Si la pareja utilizó la reproducción humana asistida para llevar a cabo el proyecto parental, es seguro que hay un deber de ayudar a los niños con estas técnicas en todas sus necesidades. Sin embargo, la aplicación del principio de crianza responsable debe extenderse a todos los embriones producidos en laboratorio, independientemente de si se introducirán o no en el útero, dando a luz a un niño.

Desde el momento en que el sistema legal de la patria establece el derecho del ciudadano a fundar una familia, incluido el uso de técnicas de fertilización artificial, la responsabilidad de los padres en cada una de las etapas médicas de la producción de embriones se vuelve esencial. quienes solo se formaron por este deseo de llevar a cabo un proyecto de crianza.

\section{EMBRIONES SOBRANTES DE LAS TÉCNICAS DE REPRODUCCIÓN HUMANA ASISTIDA}

\subsection{Vulnerabilidad del embrión humano y la necesidad de protección}

Los embriones son seres vulnerables. De hecho, todas las personas son vulnerables. Esta declaración es el resultado de un análisis del concepto mismo de vulnerabilidad, del latín

17. GAMA, Guilherme Calmon Nogueira da. Cuidado e Planejamento Familiar. In: PEREIRA, Tânia da Silva (Coord.). Cuidado e vulnerabilidade. São Paulo: Atlas, 2009, p. 239

18. REIS, Clayton. $O$ planejamento familiar: um direito de personalidade do casal. Revista Jurídica Cesumar - Mestrado, Maringá, v. 8, n. 2, p. 415-435, 2008. vulnerabilis, "que puede resultar herido". El hecho es que cualquier ser vivo "puede ser 'vulnerable' en condiciones de contingencia". Sin embargo, algunas personas tienen esta vulnerabilidad potencial, por lo que se puede decir que hasta tienen graduaciones ${ }^{19}$.

Hay ciertos grupos de personas, como las personas con discapacidad, los ancianos los niños y los adolescentes que, debido a ciertas condiciones socioeconómicas o psicofísicas, se encuentran en una situación de desigualdad en relación con los demás, lo que los convierte en víctimas. Es decir, están inevitablemente sujetos a una situación de riesgo constante. Una persona que se encuentra en esta condición "está impedida o ha disminuido la posibilidad de ejercer sus derechos", y por esta razón "necesita protección especial $^{20 " .}$

Si los niños y adolescentes son seres vulnerables por excelencia, es evidente que esta situación de vulnerabilidad también se extiende al feto $\mathrm{y}$, en consecuencia, al embrión in vitro, que tiene la capacidad de defenderse y ejercer derechos disminuidos ${ }^{21}$.

Además, el embrión in vitro no puede considerarse una persona potencial solo porque aún no se ha insertado en el útero. El ser humano atraviesa varias etapas de desarrollo, de modo que no se convierte en alguien solo como adulto, como se pensaba hasta mediados del siglo $\mathrm{XX}$, sino que es alguien desde el comienzo de su desarrollo. Lo que cambia es el grado de dependencia que este ser tiene de los demás, pero esto no elimina la calidad del ser humano ${ }^{22}$

Debido a la vulnerabilidad del embrión humano, el principio de la crianza responsable, junto con la planificación familiar, debe abarcar las primeras etapas de la formación de la vida humana.

19. BARBOZA, Heloisa Helena. Vulnerabilidade e cuidado aspectos jurídicos. In: PEREIRA, Tânia da Silva (Coord.). Cuidado e vulnerabilidade. São Paulo: Atlas, 2009, p. 110.

20. Ibid, p.113 e 114 .

21. FIGUEIREDO, Patrícia Cobianchi. O início da vida para proteção jurídica sob os ditames da Constituição e dos tratados internacionais ratificados pelo Brasil. In: GARCIA, Maria; GAMBA, Juliane Caravieri; MONTAL, Zélia Cardoso. Biodireito Constitucional: questões atuais. Rio de Janeiro: Elsevier, 2009, p. 28-29.

22. SILVA, Reinaldo Pereira e. Biodireito: a nova fronteira dos direitos humanos. São Paulo: LTr, 2003, p. 120-121. 


\subsection{La Ley de Bioseguridad y el Juicio de la Acción Directa de Constitucionalidad n. $\mathbf{3 . 5 1 0}$}

La ley no. 11.105, del 24 de marzo de 2005, llamada Ley de Bioseguridad, reguló el inc. II, IV y V del § 1 del art. 225 de la Constitución Federal, que se ocupa de la protección del patrimonio genético de Brasil, estableciendo normas de seguridad y mecanismos para la supervisión de actividades que involucran organismos genéticamente modificados y células madre embrionarias. Según Wanderlei de Paula Barreto:

El surgimiento de la biotecnología representa un hito para la ciencia jurídica y el derecho en su misión reguladora y armonizadora de las relaciones socio-legales, al mismo tiempo que constituye un factor de ruptura en el modelo articulado sobre la base de la concepción natural ${ }^{23}$.

En el art. 5 de la ley mencionada, la investigación $\mathrm{y}$ las terapias realizadas con células madre embrionarias derivadas de la reproducción humana asistida, es decir, como resultado de la fertilización in vitro, están reguladas, y los embriones sobrantes pueden destinarse a investigación científica si se cumplen los siguientes requisitos: a) si son embriones inviables o congelados antes de la fecha de publicación de la ley, en cuyo caso el período mínimo de crioconservación será de tres años; b) existe el consentimiento de los padres; c) que la investigación se someta a la supervisión de los comités de ética de la investigación; (d) una prohibición de la comercialización de embriones que cumplan estos requisitos.

Resulta que la Oficina del Procurador General presentó una Acción de Inconstitucionalidad Directa, radicada el 30 de mayo de 2005 bajo $\mathrm{n}$. 3.510 , contra el art. 5 de la Ley no. 11.105/2005, que alega un delito contra el derecho a la vida y la dignidad de la persona humana consagrada en la Constitución Federal.

En su petición inicial, el entonces Fiscal General de la República, Claudio Lemos Fonteles,

23. BARRETO, Wanderlei de Paula. Inovações sobre a personalidade jurídica $e$ os direitos da personalidade no novo Código civil brasileiro. DBJV - Mitteilungen, $n .2$ fev. 2004. Disponível em: http://www.dbjv.de/dbjv-high/ mitteilungen/04-02/DBJV_Mitteilungen_02-2004.pdf. Acesso em: 20 ago. 2019 adoptó la teoría de la concepción sobre el comienzo de la vida, argumentando que comienza con la fertilización, es decir, la unión entre el óvulo y el esperma, gametos femeninos y masculinos respectivamente. De acuerdo con Renata da Rocha:

La teoría de la concepción, considerando la primera etapa del desarrollo embrionario humano, comprende que el embrión tiene un estado moral similar al de un ser humano adulto, es decir que la vida humana comienza, para los concepcionistas, con la fertilización del embrión. Ovocito secundario por esperma. A partir de este evento, el embrión ya tiene condición para la persona, entendiendo, esta condición, la complejidad de los valores inherentes a la entidad en desarrollo ${ }^{24}$.

El 29 de mayo de 2008, Acción Directa de Inconstitucionalidad n. 3.510 fue desestimado por el Tribunal Supremo por mayoría de votos. Los votos de los Ministros de derecho, Ricardo Lewandowski, Eros Grau, Cezar Peluso y el entonces presidente Gilmar Mendes fueron parcialmente derrotados. Esto es parte del resumen de la sentencia:

CONSTITUCIONAL. ACCIÓN DIRECTA DE INCONSTITUCIONALIDAD. LEY DE SEGURIDAD DE LA BIOSEGURIDAD. ART $52 \mathrm{de}$ LA LEY N $^{\circ} 11.105,24$ DE MARZO DE 2005 (LEY DE SEGURIDAD DEL BIOS). INVESTIGACIÓN DE CÉLULAS MADRE EMBRIONARIAS. SIN RESPONSABILIDAD POR INCUMPLIMIENTO. CONSTITUCIONALIDAD DEL USO DE CÉLULAS MADRE EMBRIONARIAS EN LA INVESTIGACIÓN CIENTÍFICA PARA FINES TERAPÉUTICOS. DESCARACTERIZACIÓN DEL ABORTO. NORMAS CONSTITUCIONALES CUMPLIMIENTO DE LA LEY FUNDAMENTAL A UNA VIDA DIGNATIVA, QUE PASA EL DERECHO A LA SALUD Y LA PLANIFICACIÓN FAMILIAR. INHABILIDAD DE UTILIZAR TÉCNICA DE INTERPRETACIÓN PARA AGREGAR A LA LEY DE SEGURIDAD DE LA BIOSEGURIDAD CONTROLES INNECESARIOS QUE IMPLICAN RESTRICCIONES A LAS

24. ROCHA, Renata da. O Direito à Vida e a Pesquisa com Células Tronco: limites éticos e jurídicos. Rio de Janeiro: Elsevier, 2008, p. 75 . 
BÚSQUEDAS Y TERAPIAS DE LOS MISMOS. IMPROCEDENCIA TOTAL DE ACCIÓN²5.

La Corte Suprema Federal ha adoptado la opinión mayoritaria de que la vida protegida por el texto constitucional es la de la "persona individual", nacida, de modo que los embriones no se insertan en el útero, porque carecen de la viabilidad de transformarse en vida humana. deben protegerse solo como un activo legal, evitando "intentos inútiles o frívolos de obstaculizar su continuidad biológica natural ${ }^{26 " .}$

Además, la constitucionalidad del art. 5. $\stackrel{\text { de }}{ }$ la Ley de Bioseguridad también se basó en la libertad de investigación garantizada por el art. 5.. , IX, de la Constitución Federal y los beneficios que estas investigaciones pueden aportar a la humanidad, como una forma de garantizar el derecho a la salud.

Para la Corte Suprema de Brasil, los criterios adoptados por el art. 5 de la Ley de Bioseguridad, que enumera qué embriones pueden ser destinados a la investigación, fueron razonables, $\mathrm{y}$ algunos de los ministros, como Carmen Lucía, mencionaron que después del período de congelación de tres años, la implantación de células embrionarias criopreservadas es prácticamente ineficiente. y su destino, así como los embriones inviables, serían la "basura".

Lo que todos los Ministros de la Corte Suprema Federal no pudieron observar es la incongruencia del inc. II del art. 5 de la Ley de Bioseguridad, que prescribe así:

Art. 5 El uso de células madre embrionarias obtenidas de embriones humanos producidos por fertilización in vitro y no utilizados en el procedimiento respectivo está permitido para fines de investigación y terapia, siempre que se cumplan las siguientes condiciones:

II - son embriones congelados por 3 (tres) años o más, en la fecha de publicación de esta Ley, o que, ya congelados en la fecha de publicación de esta Ley, después de

25. BRASIL. Supremo Tribunal Federal. Ação Direta de Inconstitucionalidade n. 3.510. Relator: Ministro Ayres Britto. Julgamento: 29/05/2008.

26. Trecho extraído da ementa da ADI n. 3.510. Ibid. completar 3 (tres) años a partir de la fecha de congelación.

Se toma de la interpretación de la disposición legal antes mencionada que solo los embriones congelados hasta la fecha de publicación de la ley pueden ser destinados a la investigación. El criterio de tres años también se limita a estos embriones. Por lo tanto, todos los embriones excedentes y criopreservados después de la fecha de publicación de la Ley n. 11.105/2005, que ocurrió el 28 de marzo de 2005, no puede usarse para terapia o tratamiento.

Ives Gandra Martins y Fátima Fernandes de Souza también comentaron sobre la inconsistencia del criterio utilizado por la Ley de Bioseguridad:

Sin embargo, por arbitrario que fuera arreglar los tres años, la verdad es que no permite que los embriones congelados después de la publicación de la ley se utilicen en la investigación [...]. Estos son, por lo tanto, un pequeño número de embriones, absolutamente insuficientes para la investigación, a juzgar por los oídos de los científicos, que pueden no haber negado su derecho a la vida ${ }^{27}$.

Los doctores Álvaro Petracco, Ricardo Azambuja, Lilian Okada y Mariangela Badolotti informan que las clínicas de reproducción asistida enfrentan hoy un gran desafío: la criopreservación de embriones, ya que la Ley de Bioseguridad solo permitió el uso de congelados hasta el 28. Teniendo en cuenta que existe una limitación en la cantidad de embriones implantados en el útero como una forma de evitar embarazos múltiples, y que cada ciclo de reproducción genera un promedio de dos embriones excedentes, es alarmante pensar en la cantidad de embriones criopreservados en Brasil, lo que justifica la preocupación de médicos y clínicas ${ }^{28}$.

Además, según los autores antes mencionados, las técnicas de crioconservación permiten el

27. MARTINS, Ives Gandra da Silva; SOUZA, Fátima Fernandes Rodrigues de. Os direitos fundamentais dos seres humanos na sua forma embrionária. In: PEREIRA, T. S.; MENEZES, R. A.; BARBOZA, H. H. Vida, morte e dignidade humana. Rio de Janeiro: GZ, 2010, $p 162$.

28. PETRACCO, Alvaro, et. al. Congelamento de embriões, óvulos e tecidos ovarianos. In: DZIK, Arthur, et. al. (Ed.). Tratado de Reprodução Assistida. São Paulo: Segmento Farma, 2010, p. 353. 
envasado indefinido y viable de los embriones excedentes $^{29}$. Así, contrariamente a lo que pensaba el ministro Cármen Lúcia, el período de tres años previsto en el art. 5, inc. II, no se refirió a la efectividad de una implantación con un embrión congelado durante más de tres años, sino al tiempo considerado como mínimo para que la familia decida cuál sería el destino de ese pequeño ser, si permanecerían criopreservados para un futuro embarazo, si darían en adopción o si se destinara a la investigación científica.

Existe, por tanto, una contradicción insuperable en el art. 5 de la Ley de Bioseguridad, ya que solo los embriones congelados hasta el 28 de marzo de 2005 pueden usarse para investigación, como si no tuvieran derecho a la vida, mientras que aquellos criopreservados después de esa fecha, tendrían su vida bajo la ley brasileña. No existe una base constitucional para esta diferenciación, y los ministros de la Corte Suprema no podrían haber pasado por alto esta desigualdad material.

Nuevamente, surge la pregunta sobre el destino de los embriones criopreservados después de la fecha de publicación de la Ley n. $11.105 / 2005$. Por el momento, deben mantenerse en estas condiciones por tiempo indefinidamente. Sin embargo, se debe evitar la proliferación de material genético congelado. El Estado ya no puede omitir la cantidad de embriones que se pueden producir en cada ciclo de reproducción asistida y los padres también deben asumir la responsabilidad.

\subsection{Los peligros de una visión utilitaria del embrión humano y la dignidad de la persona humana}

La dignidad de la persona humana, desde el punto de vista de Gregorio Peces-Barba Martínez, no es en su origen un concepto jurídico, sino un constructo filosófico que expresa el valor intrínseco de la persona, que la hace única e irrepetible, siendo el centro del mundo, al mismo tiempo, centrado en el mundo, como un fin que él mismo decide qué es $y$, por lo tanto, nunca un medio ${ }^{30}$.

29. PETRACCO, Alvaro, et. al. Congelamento de embriões, óvulos e tecidos ovarianos. In: DZIK, Arthur, et. al. (Ed.). Tratado de Reprodução Assistida. São Paulo: Segmento Farma, 2010, p. 35.

30. MARTINEZ, Gregorio Peces-Barba. La dignidad de la persona desde La filosofia del derecho. 2. ed. Madrid: Dykinson,
La comprensión antes mencionada se basa en el pensamiento de Immanuel Kant, para quien la dignidad es el valor absoluto de la racionalidad humana misma. A diferencia de las cosas, que pueden considerarse irrazonables, las personas califican como seres racionales, poseedores de voluntad, lo que a su vez les da dignidad, es decir, el valor supremo y el atributo de persona humana. Si las cosas tienen un precio, los seres humanos tienen dignidad ${ }^{31}$. Ingo Wolfgang Sarlet sostiene que:

[...] como principio fundamental, la dignidad de la persona humana constituye un valor rector no solo de los derechos fundamentales sino de todo orden legal (constitucional e infraconstitucional), razón por la cual para muchos está plenamente justificado. caracterización como principio constitucional de una mayor jerarquía de valor axiológico [...].

En Acción Directa de Inconstitucionalidad n. 3.510, los ministros enfatizan la fuerza constitucional del principio de dignidad humana, dedicando innumerables páginas a explicaciones de este principio. Sin embargo, el concepto de dignidad de la persona humana en la opinión del Supremo se concatena con la búsqueda de la felicidad y la eliminación del sufrimiento, como se extrae del siguiente extracto del menú de ADI:

Sin ofender el derecho a la vida y la dignidad de la persona humana, porque la investigación con células madre embrionarias (biológicamente inviables o para los fines para los que están destinadas) significa la celebración solidaria de la vida y el estímulo para quienes están al margen del ejercicio. derechos concretos e inalienables a la felicidad de vivir con dignidad ${ }^{32}$.

Este es un concepto utilitario de la dignidad de la persona humana, ya que es digno de lo que trae placer o felicidad, y no es digno de existir con dolor o sufrimiento.

2003, p. 68.

31. KANT, Immanuel. Fundamentação à metafísica dos costumese outros escritos. São Paulo: Martin Claret, 2005, p. 17 MORAN, Narciso. La dignidad de la persona ante el desafío de la biotecnología. Revista Misión Jurídica 1 (1), p. 156.

32. BRASIL. Supremo Tribunal Federal. Ação Direta de Inconstitucionalidade n. 3.510. Relator: Ministro Ayres Britto. Julgamento: 29/05/2008, p. 333. 
El padre del utilitarismo es Jeremy Bentham, para quien "la naturaleza ha puesto a la humanidad bajo el control de dos amos soberanos: el dolor y el placer. Es solo para ellos señalar lo que debemos hacer, así como para determinar lo que realmente haremos ${ }^{33 "}$. Este es el principio de utilidad, que reconoce esta sujeción cuyo propósito es alcanzar la felicidad a través de la razón y la ley, y la felicidad consiste precisamente en "disfrutar del placer y estar libre del dolor ${ }^{34 " . ~}$

Alessandro Zenni enseña que "el principio utilitario crea medios para promover la felicidad a través de la razón y la ley (ley), aprobando o desaprobando cada acción, de acuerdo con la tendencia que parece aumentar o disminuir la felicidad de la parte cuyo interés está en juego ${ }^{35 "}$.

De hecho, ¿la ausencia de sufrimiento tiene el poder de dignificar al hombre al aumentar su felicidad? El doctor Paul Brand, junto con el periodista estadounidense Philip Yancey, narra en el libro "El regalo del dolor" una serie de experiencias de personas que, debido a su insensibilidad al dolor, sufrieron terribles consecuencias, algunas incluso fatales:

Las condiciones como la lepra, la diabetes, el alcoholismo, la esclerosis múltiple, los trastornos nerviosos y el daño en la columna también pueden provocar un estado extrañamente peligroso de insensibilidad al dolor. Irónicamente, aunque la mayoría de nosotros buscamos farmacéuticos y médicos para aliviar el dolor, estas personas están en constante peligro por su ausencia ${ }^{36}$.

Leonardo da Vinci describió el dolor y el placer como dos gemelos siameses, "formándose como una unidad, porque uno nunca viene sin el otro; $y$ se ponen de espaldas porque se oponen entre sí".

33. BENTHAM, Jeremy. Uma introdução aos princípios da moral e da legislação. Tradução de Luiz João Baraúna. In: Os Pensadores. São Paulo: Abril Cultural, 1994, p. 46.

34. Ibid, p. 60.

35. ZENNI, Alessandro Severino Vallér. A crise do direito liberal na pós-modernidade. Porto Alegre: Sergio Antonio Fabris, 2006, p. 52.

36. YANCEY, Philip; BRAND, Paul. A Dádiva da Dor: por que sentimos dor e o que podemos fazer a respeito. Tradução de Neyd Siqueira. São Paulo: Mundo Cristão, 2005, p. 13.
Sin embargo, la Corte Suprema Federal adoptó, por voto mayoritario, una visión utilitaria no solo de la dignidad de la persona humana sino también de la dignidad del embrión en sí mismo, al sostener que el uso de células madre embrionarias para la investigación no daña la dignidad humana, sino más bien, lo valora, ya que prohibir tal posibilidad sería llevar a los embriones a la indignidad, es decir, al desperdicio ${ }^{37}$.

Es peligroso comprender la dignidad de la persona humana desde una perspectiva utilitaria, porque hace que el embrión sea algo, lo que lo convierte en un medio para un fin mayor, que es la reducción del sufrimiento vinculado a la búsqueda de la felicidad y el placer. lo que llevaría a la supuesta dignidad del hombre.

Renata da Rocha advierte sobre los peligros de la investigación científica con embriones humanos, y considera que tal práctica "lo reduce a un medio ambiente" y "conduce a la reificación del ser humano, lo que le niega el derecho fundamental a la vida y la dignidad de la persona humana ${ }^{38 "}$.

En la misma línea, Reinado Pereira e Silva argumenta que debe respetarse la dignidad humana, "independientemente del grado de desarrollo individual de las potencialidades humanas, es decir, desde la concepción, aunque sea de forma extrauterina, hasta la edad adulta ${ }^{39 "}$.

Desde una concepción utilitaria de la dignidad de la persona humana, es posible preguntarse si una persona con discapacidad o enfermedad crónica tiene su dignidad disminuida. 0 si el dolor o el sufrimiento que sufren los hombres los priva de su dignidad. Obviamente, la respuesta a tales preguntas es negativa, dado que, como explica Luiz Antônio Rizatto Nunes, "la dignidad nace con la persona. Es innato para él. Inherente en su esencia. Además, "el ser humano es digno porque lo es ${ }^{40 "}$.

37. RASIL. Supremo Tribunal Federal. Ação Direta de Inconstitucionalidade n. 3.510. Relator: Ministro Ayres Britto. Julgamento: 29/05/2008, p. 362.

38. ROCHA, Renata da. O Direito à Vida e a Pesquisa com CélulasTronco: limites éticos e jurídicos. Rio de Janeiro: Elsevier, 2008, p. 155.

39. SILVA, Reinaldo Pereira e. Biodireito: a nova fronteira dos direitos humanos. São Paulo: LTr, 2003, p. 104-105.

40. NUNES, Luiz Antônio Rizzatto. O princípio constitucional da dignidade da pessoa humana: doutrina e jurisprudência. São 
Por lo tanto, si el embrión conlleva dignidad humana, no puede usarse como un medio, sobre la base de que la investigación científica podría conducir a la reducción del sufrimiento de la humanidad. Ahora, tal pensamiento implicaría la objetivación del ser humano mismo, violando así el principio de la dignidad de la persona humana, inscrita en inc. III del art. 1 de la Constitución Federal.

\section{RESPONSABILIDAD DE LOS PADRES PARA EMBRIONES DE LABORATORIO}

El derecho constitucional a la planificación familiar gratuita ha contribuido a que innumerables parejas lleven a cabo el proyecto parental a través de técnicas de reproducción humana asistida, incluida la fertilización in vitro, que implica la fertilización de varios óvulos, de modo que se forman embriones viables, algunos de estos se introducen en el útero, dependiendo de la edad de la madre y otras condiciones específicas del caso.

No existe una legislación estricta en Brasil que regule el número de embriones que se pueden formar en el laboratorio o cuántos de ellos se pueden transferir al útero del paciente en cuestión. La única regulación existente se encuentra en la Resolución no. 2013 del Consejo Federal de Medicina, que regula, en el punto "6" de los "Principios Generales" que:

6 - El número máximo de ovocitos y embriones para ser transferidos al receptor no puede exceder de cuatro. Con respecto al número de embriones a transferir, se hacen las siguientes recomendaciones: a) mujeres de hasta 35 años: hasta 2 embriones; b) mujeres entre 36 y 39 años: hasta 3 embriones; c) mujeres entre 40 y 50 años: hasta 4 embriones; d) en situaciones de donación de óvulos y embriones, se considera la edad del donante al momento de la recolección de óvulos.

Dada esta falta de regulación legislativa y administrativa, las clínicas y laboratorios de reproducción humana son libres de, de acuerdo con los pacientes, fertilizar varios óvulos, a pesar de que solo una parte de los embriones obtenidos están realmente implantados, y surge la pregunta

Paulo: Saraiva, 2002, p. 49. de qué pasará o quién se otorgarán los embriones sobrantes.

Renata da Rocha ${ }^{41}$ cita el ejemplo de Alemania, cuya legislación requiere que todos los embriones obtenidos sean transferidos al útero. Ives Grandra Martins $^{42}$ también cita el ejemplo de Austria e Italia, en el que también se prohíbe la producción de embriones excedentes.

Los doctores Newton Eduardo Busso y Cristiano Eduardo Busso explican que para obtener varios ovocitos $y$, en consecuencia, múltiples embriones, se requieren protocolos de estimulación ovárica de alto costo, que pueden causar complicaciones graves, como el síndrome de hiperestimulación ovárica, responsable del aumento del volumen intravenoso, complicado por trombosis y / o insuficiencia renal, hepática y respiratoria, puede ser fatal en algunos $\operatorname{casos}^{43}$.

Para evitar tantos daños, los investigadores han sugerido el uso de protocolos de estimulación mínimos, con dosis bajas de medicamentos, o incluso el ciclo natural de reproducción asistida, en el que no se usa ningún medicamento, produciendo un solo embrión. Estos protocolos, además de causar menos daño a la salud de las mujeres, pueden ser una posible solución al problema de los embriones excedentes ${ }^{44}$.

En la Resolución no. 2.013 / 2013, el Consejo Federal de Medicina declara en el Capítulo V, punto "3" que "el número total de embriones producidos en laboratorio se comunicará a los pacientes para decidir cuántos embriones se transferirán recientemente, y se deberán obtener excedentes viables crioconservado". Sin embargo, esta congelación de los embriones no es indefinida, ya que el ítem 4 del mismo capítulo permite que los embriones sean descartados después de cinco años de criopreservación "si la voluntad de los

41. ROCHA, Renata da. O Direito à Vida e a Pesquisa com CélulasTronco: limites éticos e jurídicos. Rio de Janeiro: Elsevier, 2008, p. 50

42. MARTINS, Ives Gandra da Silva; SOUZA, Fátima Fernandes Rodrigues de. Os direitos fundamentais dos seres humanos na sua forma embrionária. In: PEREIRA, T. S.; MENEZES, R. A.; BARBOZA, H. H. Vida, morte e dignidade humana. Rio de Janeiro: GZ, 2010, $p 163$.

43. BUSSO, Newton Eduardo; BUSSO, Cristiano Eduardo. Indução da ovolução: ciclo natural e minimamente induzido. In: DZIK, Arthur, et. al. (Ed.). Tratado de Reprodução Assistida. São Paulo: Segmento Farma, 2010, p. 240.

44. Ibid, p. 241-242. 
pacientes no solo para la investigación con células madre como lo exige la Ley de Bioseguridad".

Además de permitir el destino para la investigación de embriones criopreservados, independientemente de si se formaron antes o después de la Ley de Bioseguridad, la Resolución en consideración prevé la posibilidad de eliminar a estos seres, siempre que los pacientes tengan su consentimiento.

Existe un utilitarismo extremo por parte del Consejo Federal de Medicina y clínicas de reproducción, que extraen la mayor cantidad posible de ovocitos de las mujeres, produciendo así embriones múltiples, muchos de los cuales tienen conocimiento en el campo y en los propios pacientes. Ni siquiera será utilizado. Para el posible riesgo de embriones implantados en el útero materno no se desarrollará, la clínica ya tendrá otros disponibles para su reutilización, lo que reduce los costos.

La planificación familiar gratuita debe ejercerse de manera vinculada al principio de una crianza responsable. El deseo de una pareja de tener hijos no puede legitimar un abuso constante de la objetivación del embrión que culmina en su propio desprecio por la vida humana.

La ausencia de límites en la extracción de ovocitos de las mujeres y la producción de embriones puede conducir a situaciones más extremas, como la eugenesia, donde los pacientes desean que se produzcan múltiples embriones para que elijan el sexo y las características físicas de sus hijos, eliminando así la necesidad, aquellos que son "indeseables" para ellos.

Se menciona el diagnóstico genético previo a la implantación de embriones, que permite a los médicos y científicos diagnosticar cambios genéticos que causan enfermedades. El príncipe William y su esposa Kate Middleton han recurrido a esta técnica para tener recientemente una hija libre del riesgo de desarrollar cáncer de seno en un $75 \%{ }^{45}$.

Además, la técnica se ha utilizado ampliamente en parejas que ya tienen un hijo con una enfermedad genética para la cual la única cura

45. TIRABOSCHI, Juliana. Crianças sob medida.
Disponível em: Disponível em: <http://revistagalileu.globo.com/Revista/
Galileu/0,EDR86212-7855,00.html>. Acesso em 05 set. 2013. es un trasplante de médula realizado por una persona compatible. En estos casos, se producen varios embriones en el laboratorio para que solo uno que se ajuste a las características prescritas por el médico se implante en el útero de la madre.

Esto es lo que sucedió en Brasil con Maria Vitória, una niña de seis años que sufre de talasemia mayor, que se curó después de someterse a un trasplante de médula ósea y cordón umbilical donado por su hermana, Maria Clara, de un año, quien nació después de haber sido genéticamente seleccionada, ya que además de no tener el gen de la talasemia, era 100\% compatible con su hermana mayor. Resulta que para la generación de María Clara, se produjeron diez embriones en el laboratorio, de los cuales solo dos se insertaron en el útero de la madre, y solo uno se desarrolló ${ }^{46}$.

El propio Consejo Médico Federal autoriza en el Capítulo 6 de la Resolución 2.013-2013, el uso del diagnóstico previo a la implantación para producir un "bebe medicamento":

2 - Las técnicas de AR también se pueden usar para tipear el sistema embrionario HLA, con el propósito de seleccionar embriones compatibles con HLA con cualquier hijo de la pareja ya afectada por la enfermedad, enfermedad que tiene como modalidad de tratamiento eficaz el trasplante de células madre o órganos.

Una vez más, se observa el carácter utilitario del uso de técnicas de reproducción asistida junto con el diagnóstico previo a la implantación para evitar el dolor, los riesgos de enfermedad y felicidad, la cura de un niño enfermo. Sin embargo, para lograr este fin, se produjeron varios embriones, sabiendo que los padres probablemente nunca serían implantados en el útero materno.

Por lo tanto, debe cuestionarse la responsabilidad de los padres con respecto a todos los embriones producidos como resultado del uso de técnicas de fertilización artificial. En

46. BASSETE, Fernanda. Transplante inédito de cordão e medula cura menina com talassemia. Disponível em: <http:// www.estadao.com.br/noticias/impresso,transplante-ineditode-cordao-e-medula-cura-menina-com-talassemia-,1022797,0. htm>. Acesso em 05 ago. 2019. 
ADI n. 3.510, la Corte Suprema Federal declaró en el ítem $V$ que:

La elección de la pareja para un proceso "in vitro" de fertilización artificial de óvulos es un derecho implícito de la misma matriz constitucional, sin implicar para esta pareja el deber legal del uso reproductivo de todos los embriones genéticamente viables que finalmente se formen.

De hecho, obligar a una mujer a inseminar todos los ovocitos fertilizados viables en su útero sería absurdo y peligroso para la salud de la madre y el bebé. Sin embargo, eliminar la responsabilidad del destino de los embriones excedentes de la pareja es violar el derecho a la planificación familiar gratuita asociada con los principios de crianza responsable y dignidad humana.

Al plantear el problema de la ética en la producción de bebés "a medida", ya sea para prevenir una enfermedad congénita o para ser el donante de un hermano enfermo, uno debe considerar el destino de los innumerables embriones viables que son despreciados simplemente porque no encajan en la "prescripción" deseada por los padres.

Del mismo modo, uno debe repensar la práctica habitual de fertilización de numerosos ovocitos como una forma de poner a disposición de los pacientes varios embriones, lo que permite que, si los implantados en la madre no se desarrollan, se puedan utilizar los otros, evitando así más gastos con la extracción de ovocitos, ya que los costos de la reproducción asistida se deben en gran medida a las hormonas de estimulación ovárica.

Por lo tanto, la pareja o el paciente que busca una clínica de reproducción asistida debe ser consciente de que, para generar el niño deseado, ya sea "a medida" o no, puede ser necesaria la producción de varios embriones. Siempre que sea posible, se debe evitar el excedente embrionario, pero si es así, el destino de quienes son excedentes también es responsabilidad de quienes los planearon. No hay obligación de que todos se inserten en el útero, sin embargo, permitir el descarte sería un desprecio por la vida humana.

Es necesario que el Poder Legislativo se exprese y regule el tema. Primero, se debe establecer un número máximo de ovocitos para ser fertilizados en cada intento de embarazo, incluso en el caso de bebés "a medida". Además, teniendo en cuenta que la Ley de Bioseguridad solo permitía la investigación de embriones producidos hasta su promulgación (2005), siempre que no haya cambios legislativos, los embriones excedentes de técnicas reproductivas adoptados en una fecha posterior no deberían ser enviados para investigación. En este caso, son los pacientes los que deben asumir los costos de su criopreservación, permitiendo siempre la adopción.

Si existiera una limitación en la producción de embriones por técnica, así como la obligación de la pareja o la persona que buscó una clínica de dar cuenta de los costos de la criopreservación de todos los embriones excedentes, que tampoco pueden ser bajos, esas personas reflexionarían sobre la fertilización excesiva de los embriones.

El principio de la paternidad responsable tiene implicaciones que van más allá de la vida de un niño o adolescente. Cuando una persona desea llevar a cabo el proyecto parental a través de técnicas artificiales, su responsabilidad comienza desde el momento en que se fecundan los ovocitos, cuando ya existe una formación de vida humana en sentido amplio, que merece protección. Pensar lo contrario es demasiado peligroso, porque la adopción del utilitarismo excesivo puede conducir a una cosificación del embrión y, en consecuencia, del ser humano mismo.

\section{CONCLUSIÓN}

La creciente demanda de métodos de reproducción humana asistida revela el anhelo de crianza por parte de parejas infértiles o de quienes dependen del diagnóstico genético previo a la implantación para elegir embriones que no tienen anomalías congénitas o que son compatibles con un niño que necesita un trasplante de médula ósea, por ejemplo.

Es derecho de cualquier ciudadano a la planificación familiar; sin embargo, el uso de técnicas de fertilización artificial también debe estar relacionado con el principio de la paternidad responsable y la dignidad de la persona humana, como lo exige el art. 226, §7으 de la Constitución Federal. Dichos principios implican no solo la obligación de los padres de garantizar que 
los niños y sus hijos tengan garantizados sus derechos, sino también la responsabilidad del destino de todos los embriones producidos en la fertilización in vitro.

Los embriones son seres vulnerables que necesitan protección especial porque representan la vida humana, aunque en un sentido amplio. El uso de reproducción asistida significa que culmina en la producción de embriones excedentes, y la Ley de Bioseguridad regula la admisibilidad de estos embriones para ser destinados a la investigación científica, siempre que los requisitos del art. 5, entre los cuales se destaca la necesidad de formarse antes de la promulgación de la ley mencionada, y ser criopreservados durante al menos tres años (ítem III).

La mencionada Ley fue objeto de la Acción Directa de Inconstitucionalidad n. 3.510, que fue desestimado por mayoría de votos, sin que los Ministros del Tribunal Federal Supremo se dieran cuenta de la inconsistencia del art. 5, III. La mayoría de los votos ganadores se basaron en el beneficio que la investigación con células madre embrionarias podría fornecer a las personas con discapacidades o enfermos crónicos, para que pudieran lograr una vida feliz, observando así, el principio de la dignidad de la persona humana.

Según los ministros, la atribución de embriones excedentes para la investigación los dignifica, ya que tiene la posibilidad de reducir el sufrimiento y aumentar la felicidad de aquellos que pueden beneficiarse de los resultados de tales experimentos. Sin embargo, esta es una visión utilitaria de la dignidad de la persona humana, y tiene el peligro de objetivar al hombre, convirtiéndolo en un medio para un fin mayor, que es la felicidad de la humanidad, como si el dolor pudiera ser algo indigno.

El derecho a la planificación familiar a través de técnicas de reproducción asistida no puede legitimar una visión utilitaria del embrión humano que, en las consecuencias finales, permitirá que la fertilización in vitro se use como una verdadera forma de eugenesia, ya que la implantación permite a los científicos verificar anormalidades, así como el género e incluso características personales como ojos, piel, color de cabello, etc.

Hay una responsabilidad por parte de aquellos que están dispuestos a tener un hijo artificialmente, y esto se deriva del principio de una crianza responsable. Por lo tanto, los embriones excedentes no son solo una preocupación del Estado o de los científicos, ya que esto sería relegar la vida humana a una mera utilidad, que sería producir otras vidas humanas más "saludables" o el estereotipo deseado por los padres.

Se debe evitar que un número incalculable de embriones excedentes sea criopreservado, y la legislatura debe actuar creando una ley que limite el número de embriones producidos en cada ciclo de reproducción humana asistida, como es el caso en Alemania y en Italia. Hasta ahora solo existe una regulación del Consejo Federal de Medicina, que tampoco aborda este aspecto.

Además, teniendo en cuenta que la Ley de Bioseguridad no permite que los embriones producidos después de la promulgación se destinen a la investigación, a los pacientes se les debe cobrar el costo de crioconservar los embriones excedentes a menos que sean donados para su adopción.

La decisión del Tribunal Supremo Federal no puede interpretarse en la Acción Directa de Inconstitucionalidad n. 3.510 en el sentido de desprecio por el embrión humano. La visión utilitaria adoptada por el Tribunal Constitucional brasileño es peligrosa. Los diferentes órganos deben adoptar una postura en defensa de la vida humana, regulando todas las etapas de la reproducción asistida, incluida la responsabilidad de los padres de todos los embriones producidos, independientemente de si están implantados en el útero. 


\section{BIBLIOGRAFÍA}

- BARBOZA, Heloisa Helena. Vulnerabilidade e cuidado: aspectos jurídicos. In: PEREIRA, Tânia da Silva (Coord.). Cuidado e vulnerabilidade. São Paulo: Atlas, 2009.

- BARRETO, Wanderlei de Paula. Inovações sobre a personalidade jurídica e os direitos da personalidade no novo Código civil brasileiro. DBJV - Mitteilungen, n. 2, fev. 2004. Disponível em: http://www.dbjv. de/dbjv-high/mitteilungen/04-02/DBJV_ Mitteilungen_02-2004.pdf. Acesso em: 20 ago. 2019.

- BASSETE, Fernanda. Transplante inédito de cordãoemedulacuramenina comtalassemia. Disponível em: <http://www.estadao.com. $\mathrm{br} /$ noticias/impresso,transplante-ineditode-cordao-e-medula-cura-menina-comtalassemia-,1022797,0.htm>. Acesso em 05 ago. 2019.

- BENTHAM, Jeremy. Uma introdução aos princípios da moral e da legislação. Tradução de Luiz João Baraúna. In: Os Pensadores. São Paulo: Abril Cultural, 1994.

- BRASIL. Supremo Tribunal Federal. Ação Direta de Inconstitucionalidade n. 3.510. Relator: Ministro Ayres Britto. Julgamento: 29/05/2008.

- BRASIL. Supremo Tribunal Federal. Ação Direta de Inconstitucionalidade n. 3.510. Relator: Ministro Ayres Britto. Julgamento: 29/05/2008.

- BRASIL. Supremo Tribunal Federal. Ação Direta de Inconstitucionalidade n. 3.510. Relator: Ministro Ayres Britto. Julgamento: 29/05/2008.

- BUSSO, Newton Eduardo; BUSSO, Cristiano Eduardo. Indução da ovolução: ciclo natural e minimamente induzido. In: DZIK, Arthur, et. al. (Ed.). Tratado de Reprodução Assistida. São Paulo: Segmento Farma, 2010.

- CARDIN, Valéria Silva Galdino. Do planejamento familiar, da paternidade responsável e das políticas públicas. IBDFAM, Belo Horizonte. Disponível em: <www.ibdfam.org.br>. Acesso em: 01 ago. 2019.

- CRUZ, Ivelise Fonseca da. Efeitos da reprodução humana assistida. São Paulo: SRS Editora, 2008.

- FIGUEIREDO, Patrícia Cobianchi. 0 início da vida para proteção jurídica sob os ditames da Constituição e dos tratados internacionais ratificados pelo Brasil. In: GARCIA, Maria; GAMBA, Juliane Caravieri; MONTAL, Zélia Cardoso. Biodireito Constitucional: questões atuais. Rio de Janeiro: Elsevier, 2009.

- GAMA, Guilherme Calmon Nogueira da. A nova filiação: o biodireito e as relações parentais: o estabelecimento da parentalidade-filiação e os efeitos jurídicos da reprodução assistida heteróloga. Rio de Janeiro: Renovar: 2003.

- GAMA, Guilherme Calmon Nogueira da. Cuidado e Planejamento Familiar. In: PEREIRA, Tânia da Silva (Coord.). Cuidado e vulnerabilidade. São Paulo: Atlas, 2009.

- KANT, Immanuel. Fundamentação à metafísica dos costumes e outros escritos. São Paulo: Martin Claret, 2005.

- LEITE, Eduardo de Oliveira. Procriações artificiais e o direito: aspectos médicos, religiosos, psicológicos, éticos e jurídicos. São Paulo: Revista dos Tribunais, 1995.

- MARTINEZ, Gregorio Peces-Barba. La dignidad de la persona desde La filosofia del derecho. 2. ed. Madrid: Dykinson, 2003.

- MARTINS, Ives Gandra da Silva; SOUZA, Fátima Fernandes Rodrigues de. Os direitos fundamentais dos seres humanos na sua forma embrionária. In: PEREIRA, T. S.; MENEZES, R. A.; BARBOZA, H. H. Vida, morte e dignidade humana. Rio de Janeiro: GZ, 2010.

- Moran Martínez, Narciso. La dignidad 
de la persona ante el desafío de la biotecnología. Revista Misión Jurídica 1 (1): 149-175, 2008. DOI: https://doi. org/10.25058/1794600X.7

- NUNES, Luiz Antônio Rizzatto. 0 princípio constitucional da dignidade da pessoa humana: doutrina e jurisprudência. São Paulo: Saraiva, 2002.

- PETRACCO, Alvaro, et. al. Congelamento de embriões, óvulos e tecidos ovarianos. In: DZIK, Arthur, et. al. (Ed.). Tratado de Reprodução Assistida. São Paulo: Segmento Farma, 2010.

- PETRACCO, Alvaro, et. al. Congelamento de embriões, óvulos e tecidos ovarianos. In: DZIK, Arthur, et. al. (Ed.). Tratado de Reprodução Assistida. São Paulo: Segmento Farma, 2010.

- PINTO-BARROS, José. Planeamento familiar: aborto e o direito. Coimbra: Coimbra, 1992.

- QUEIROZ, Juliane Fernandes. Paternidade: aspectos jurídicos e técnicas de inseminação artificial. Belo Horizonte: Del Rey, 2001.

- RED LATINOAMERICANA DE REPRODUCCIÓN ASISTIDA. Registro Latinoamericano de Reproducción Asistida de 1999: 10 años. Disponível em: <http://www.redlara.com/aa_portugues/ registro_anual.asp?categoria=Registros Anuais\&cadastroid=23>. Acesso em 26 ago. 2019.

- REIS, Clayton. O planejamento familiar: um direito de personalidade do casal. Revista Jurídica Cesumar - Mestrado, Maringá, v. 8, n. 2, p. 415-435, 2008.

- RIBEIRO, Gustavo Pereira Leite. Breve comentário sobre aspectos destacados da reprodução humana assistida. In: SÁ, Maria de Fátima Freire de (Coord.). Biodireito. Belo Horizonte: Del Rey, 2002.

- ROCHA, Renata da. O Direito à Vida e a Pesquisa com Células-Tronco: limites éticos e jurídicos. Rio de Janeiro: Elsevier, 2008.

- RODRIGUES JUNIOR, Walsir Edson Rodrigues; BORGES, Janice Silveira. Alteração da vontade na utilização das técnicas de reprodução assistida. In: TEIXEIRA, Ana Carolina Brochado; RIBEIRO, Gustavo Pereira Leite (Coord.). Manual de direito das famílias e das sucessões. Belo Horizonte: Del Rey: Mandamentos, 2008.

- SÁ, Maria de Fátima Freire; NAVES, Bruno Torquato de Oliveira. Manual de Biodireito. Belo Horizonte: Del Rey, 2009.

- SILVA, Reinaldo Pereira e. Biodireito: a nova fronteira dos direitos humanos. São Paulo: LTr, 2003.

- SILVA, Reinaldo Pereira e. Biodireito: a nova fronteira dos direitos humanos. São Paulo: LTr, 2003.

- TIRABOSCHI, Juliana. Crianças sob medida. Disponível em: <http:// revistagalileu.globo.com/Revista / Galileu/0,EDR86212-7855,00.html>. Acesso em 05 set. 2013.

- UNITEDNATIONS. Internacional Conference on Population and Development. Disponível em: <http://www.un.org/popin/icpd2.htm $>$. Acesso em 02 ago. 2019.

- YANCEY, Philip; BRAND, Paul. A Dádiva da Dor: por que sentimos dor e o que podemos fazer a respeito. Tradução de Neyd Siqueira. São Paulo: Mundo Cristão, 2005.

- ZENNI, Alessandro Severino Vallér. A crise do direito liberal na pós-modernidade. Porto Alegre: Sergio Antonio Fabris, 2006. 